\title{
NT-proBNP can be used to detect right ventricular systolic dysfunction in pulmonary hypertension
}

\author{
K.G. Blyth*\#, B.A. Groenning" , P.B. Mark\#, T.N. Martin\#, J.E. Foster", T. Steedman\#, \\ J.J. Morton ", H.J. Dargie" ${ }^{\#}$ and A.J. Peacock*
}

ABSTRACT: Right ventricular systolic dysfunction (RVSD) at baseline (pre-treatment) predicts early death in patients with pulmonary hypertension (PH). However, RVSD can only be detected reliably by prohibitively invasive or expensive techniques. $\mathrm{N}$-terminal B-type natriuretic peptide concentration ([NT-proBNP]) correlates with RV function in PH; however, an [NT-proBNP] threshold that indicates RVSD in individual patients has not previously been determined.

Twenty-five patients with $\mathrm{PH}$ (pulmonary arterial hypertension $(n=19)$ or chronic thromboembolic PH $(n=6)$ ) underwent cardiovascular magnetic resonance $(C M R)$ imaging and NT-proBNP measurement at baseline. [NT-proBNP] was correlated against RV dimensions and ejection fraction (RVEF) measured directly by CMR imaging. The ability of NT-proBNP to detect RVSD (defined as a CMR-derived RVEF $>2$ SDs below control values) was tested and predictors of [NTproBNP] identified.

[NT-proBNP] correlated negatively with RVEF. RVSD was present in nine out of 25 patients. An [NT-proBNP] threshold of $1,685 \mathrm{pg} \cdot \mathrm{mL}^{-1}$ was sensitive $(100 \%)$ and specific $(94 \%)$ in detecting RVSD. RVEF and RV mass index independently predicted [NT-proBNP].

In pulmonary hypertension, a baseline $\mathrm{N}$-terminal B-type natriuretic peptide concentration of $>1,685 \mathrm{ng} \cdot \mathrm{L}^{-1}$ suggests right ventricular systolic dysfunction, and thus an increased risk of early death. N-terminal B-type natriuretic peptide could prove useful as an objective, noninvasive means of identifying patients with pulmonary hypertension who have right ventricular systolic dysfunction at presentation.

KEYWORDS: Magnetic resonance imaging, natriuretic peptide, pulmonary hypertension, right ventricular function

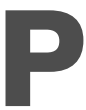

ulmonary hypertension $(\mathrm{PH})$ is a rare condition characterised by increased resistance to pulmonary blood flow, progressive right ventricular (RV) systolic dysfunction (RVSD) and early death. Without specific treatment, up to $50 \%$ of patients diagnosed with $\mathrm{PH}$ will die within 2 yrs, usually as a result of RVSD [1]. In earlier studies that identified RVSD either by invasive haemodynamic measurements [1-5] or by the detection of overt clinical signs (i.e. patients within class IV of the World Health Organization classification of disease severity) [1], evidence of RVSD at baseline (i.e. pre-treatment) was associated with an increased mortality risk.

Accurate assessment of baseline RV function is therefore desirable in all patients with $\mathrm{PH}$. This information can help identify individuals in whom

For editorial comments see page 622 . prompt invasive assessment and the initiation of disease-targeted therapy, is appropriate. Early RV dysfunction might be difficult to detect on clinical examination, therefore transthoracic echocardiography is often used for this purpose [6]. Although inexpensive and widely available, RV ejection fraction (RVEF) can only be estimated indirectly from measurements acquired in two dimensions by echocardiography. Variables derived by this method that reflect RV function and provide useful prognostic information in $\mathrm{PH}$ are either complicated to define and therefore reliant upon an experienced operator (e.g. the Tei index) [7], or most frequently detected in patients in whom RV failure is already clinically overt (e.g. a pericardial effusion) [2].

Cardiovascular magnetic resonance (CMR) imaging has recently emerged as the new gold standard for assessment of the $\mathrm{RV}$ in $\mathrm{PH}$ and
AFFILIATIONS

*Scottish Pulmonary Vascular Unit,

\#Glasgow Cardiac Magnetic

Resonance Unit, and

"BHF Cardiovascular Research

Centre, University of Glasgow,

Glasgow, UK.

CORRESPONDENCE

A.J. Peacock

Scottish Pulmonary Vascular Unit

Western Infirmary

Dumbarton Road

Glasgow G11 6NT

UK

Fax: 441412116334

E-mail: apeacock@udcf.gla.ac.uk

Received:

July 202006

Accepted after revision:

November 202006

STATEMENT OF INTEREST

None declared.
European Respiratory Journal Print ISSN 0903-1936 Online ISSN 1399-3003 
other diseases $[8,9]$; it allows image acquisition in any plane and at almost any angle, allowing direct measurement of RV volumes and RVEF. At present, CMR imaging remains too expensive for routine clinical use and is therefore not available in many $\mathrm{PH}$ centres. An alternative noninvasive method of identifying baseline RVSD in $\mathrm{PH}$ that is objective, operator independent and widely available would, therefore, be clinically useful.

B-type natriuretic peptide (BNP) and N-terminal-proBNP (NTproBNP) are released from both cardiac ventricles in response to raised chamber pressure or volume overload [10]. Previous studies have shown that circulating BNP concentration correlates with invasive pulmonary haemodynamics [11, 12], RVEF measured by computed tomography (CT) [12], survival $[13,14]$, and the response to therapy $[15,16]$ in $\mathrm{PH}$ patients. NT-proBNP, which is biologically inactive, is more stable in vivo and in vitro than BNP [17] and can therefore be used instead of BNP as a cardiovascular biomarker in various disease states. Circulating NT-proBNP concentration ([NTproBNP]) has recently been shown to correlate with invasive pulmonary haemodynamics [18], survival- and echocardiography-derived measures of RV function in $\mathrm{PH}$ [19]. However, a threshold [NT-proBNP] indicating that RVSD is present in an individual patient has yet to be determined, perhaps because of insufficient precision in the previous reference method of RV systolic function measurement (echocardiography).

The present authors aimed to relate [NT-proBNP] to RV volumes and systolic function measured directly by CMR imaging and to identify an [NT-proBNP] threshold for the detection of RVSD in patients with PH at baseline.

\section{METHODS}

\section{Patients}

A prospective cross-sectional study was performed. Thirty consecutive patients were recruited who attended for diagnosis and baseline assessment at the Scottish Pulmonary Vascular Unit (Glasgow, UK). All subjects underwent routine clinical assessment, including right heart catheterisation to establish a diagnosis of PH. The following were used as inclusion criteria for the study: 1) a diagnosis of either pulmonary arterial hypertension (PAH) or chronic thromboembolic PH (CTEPH) reached by conventional diagnostic methods [6]; and 2) informed written consent to a study protocol approved by the local institutional review committee.

Patients were excluded from the study (after review of their past medical history, admission blood tests and transthoracic echocardiogram and before CMR imaging and NT-proBNP measurement) if they met any of the following exclusion criteria. 1) Evidence of congenital heart disease (CHD), either at echocardiography or as a previous diagnosis. Patients with CHD were excluded because differing patterns of natriuretic peptide release have been demonstrated in conditions that cause RV volume overload, such as CHD, in comparison with those that cause RV pressure overload (e.g. PAH and CTEPH) [20]. 2) A history of any other condition that might cause elevation of [NT-proBNP]. These include ischaemic heart disease [21]; myocardial infarction [22]; left ventricular (LV) systolic dysfunction [23]; systemic hypertension [24]; left-sided valvular heart disease [25]; chronic renal impairment [26] or an abnormal serum creatinine on admission to the Scottish Pulmonary Vascular Unit (normal was defined as $<120 \mu \mathrm{mol} \cdot \mathrm{L}^{-1}$ ); and diabetes mellitus [27] or a fasting blood glucose on admission to the Scottish Pulmonary Vascular Unit of $>6.1 \mathrm{mmol} \cdot \mathrm{L}^{-1}$. 3) $\mathrm{CMR}$-related exclusion criteria included an indwelling cardiac pacemaker and claustrophobia.

On the basis of these criteria, five out of 30 patients were excluded from the final analysis (atrial septal defect (two out of five), chronic renal impairment (one out of five), significant mitral regurgitation (one out of five) and systemic hypertension (one out of five)). The remaining 25 subjects underwent CMR imaging and venous blood sampling for [NT-proBNP] within $24 \mathrm{~h}$ of invasive assessment. The final diagnoses reached in these 25 patients were as follows: idiopathic PAH in 11 out of 25, CTEPH in six out of 25 and PAH associated with connective tissue disease (PAH-CTD) in eight out of 25. At the time of the study, no patient had received any diseasetargeted therapy (i.e. prostacyclin analogues, bosentan, sildenafil or calcium-channel blockers) for $\mathrm{PH}$.

Twelve control subjects, with no history of any cardiorespiratory disease, underwent CMR imaging to provide local control values for ventricular dimensions and function. All control subjects were staff of the Western Infirmary, Glasgow, UK, and were subject to the same exclusion criteria as $\mathrm{PH}$ patients. Controls were approached individually and asked to participate. All controls gave informed written consent but did not undergo right heart catheterisation or NT-proBNP measurement.

There were no significant differences between $\mathrm{PH}$ patients and controls in mean $\pm \mathrm{SD}$ age (PH: $60 \pm 12$, controls: $57 \pm 12$, $\mathrm{p}=0.455)$ or mean systemic blood pressure (PH: 95 \pm 13 , controls: $92 \pm 17, \mathrm{p}=0.536)$. PH (17 males and eight females) and control populations (eight males and four females) were well sex matched.

\section{Venous blood sampling and measurement of NT-proBNP}

After $\geqslant 20 \mathrm{~min}$ of recumbent rest, $5 \mathrm{~mL}$ of venous blood was drawn from the antecubital fossa of all $25 \mathrm{PH}$ patients immediately prior to CMR imaging. Blood samples were drawn into vacuum-sealed containers containing ethylenediamine tetraacetic acid and immediately centrifuged using a PK110 centrifuge (ALC, Winchester, VA, USA). Supernatant was then removed and individual samples were coded, labelled and stored at $-80^{\circ} \mathrm{C}$ until analysis.

NT-proBNP analysis was performed on an ELECSYS 2010 bench top analyser utilising a chemiluminescent assay with a coefficient of variation $<5 \%$ (Roche Diagnostics, Lewes, UK). All biochemical analyses were performed by a single operator (J.J. Morton) who was blinded to haemodynamic, CMR and clinical results. NT-proBNP measurements are subsequently quoted as plasma concentration $\left(\mathrm{ng} \cdot \mathrm{L}^{-1}\right)$.

\section{CMR image acquisition}

CMR imaging was undertaken on a $1.5 \mathrm{~T}$ MRI scanner (Sonata Magnetom; Siemens, Erlangen, Germany) using a protocol recently described in detail [28]. An identical CMR protocol was followed in the control subjects. Fast imaging with steadystate free precession cines (TrueFISP; Siemens) were utilised throughout. Methodological details that are of particular 
importance include standardised imaging parameters of repetition time, echo time, flip angle, voxel size, field of view $=3.14 \mathrm{~ms}, 1.6 \mathrm{~ms}, 60^{\circ}, 2.2 \times 1.3 \times 8.0 \mathrm{~mm}, 340 \mathrm{~mm} ; 8-\mathrm{mm}$ imaging slices were used with a $2-\mathrm{mm}$ interslice gap. Shortaxis imaging was initiated at the atrioventricular valve plane identified on a horizontal long-axis view of the heart, and then propagated sequentially to the cardiac apex, providing complete coverage of left and right ventricles.

\section{CMR image analysis}

CMR images in $\mathrm{PH}$ patients and controls were analysed by a single operator (K.G. Blyth) using the Argus analysis software (Siemens). Individual scans were coded by number and analysed in batches by K.G. Blyth, who was blinded to the identity and haemodynamic results of any given subject at the time of analysis. CMR analysis was performed before blood samples were analysed for NT-proBNP levels. RV and LV volumes (RV end-diastolic, RV end-systolic, LV end-diastolic and LV end-systolic volumes) were determined by manual planimetry of selected short-axis images, as described previously $[29,30]$. RV and LV ventricular stroke volume (RVSV and LVSV), RVEF and LV ejection fraction, and RV and LV mass (RVM and LVM) were determined as previously described $[29,30]$. RVM was determined as RV free wall mass. The interventricular septum was considered part of the LV. RVM index was determined as RVM/LVM [31]. LV and RV volumes were corrected for body surface area and reported as indexed measurements (RV end-diastolic, RV end-systolic, LV end-diastolic and LV end-systolic volume indices).

\section{Clinical assessment and right heart catheterisation}

A standard diagnostic algorithm [6] was employed in the clinical assessment of all $\mathrm{PH}$ patients studied. This included right heart catheterisation using established techniques [6], isotope perfusion lung scanning and CT pulmonary angiography in all patients. If CTEPH was suspected following these initial investigations, selective pulmonary angiography was performed in the catheterisation laboratory (CTEPH was confirmed using this algorithm in six out of $25 \mathrm{PH}$ patents).

\section{Statistical analysis}

For all variables, a normal distribution was verified using histograms and Kolmogorov-Smirnov tests. Non-normally distributed values ([NT-proBNP] and right atrial pressure) were logarithmically transformed and all correlation analyses were performed using Pearson's method. Comparisons between $\mathrm{PH}$ patients and controls (and between subgroups of $\mathrm{PH}$ patients) were made using an independent samples (unpaired) t-test (using Welch's correction if appropriate).

Contingency tables $(2 \times 2)$ were used to calculate the sensitivity and specificity of various plasma concentrations of NTproBNP as a means of detecting RVSD. RVSD was defined as an RVEF $<42 \%$ (this constituted an RVEF $>2$ sDs below the mean RVEF of the control population $(66 \pm 7 \%))$. The plasma [NT-proBNP] with the greatest diagnostic accuracy (that which produced the lowest number of false-positive and falsenegative results) was chosen as a "threshold" value for the detection of RVSD. Negative and positive predictive values for results either side of this NT-proBNP threshold were then calculated. The implications of an above-threshold result were quantified by likelihood ratios and Fisher's exact test.

To identify independent predictor(s) of circulating [NTproBNP], variables significantly associated with [NTproBNP] (RV end-diastolic volume and RV end-systolic volume indices, RVEF, RVM index, LVSV index, mean pulmonary arterial pressure $(P$ pa $)$, systolic $P$ pa, diastolic $P$ pa, cardiac index, pulmonary vascular resistance and mixed venous oxygen saturation $\left.\left(\mathrm{S} v, \mathrm{O}_{2}\right)\right)$ were entered into a multivariable stepwise linear regression model, in which NTproBNP was the dependent variable. Covariables with a correlation coefficient $\geqslant 0.8$ were tested within separate regression models to avoid the effects of co-linearity. All statistical analyses were two-sided and assumed a significance level of $5 \%$. All values are presented as mean $\pm 1 \mathrm{SD}$, unless otherwise stated.

\section{RESULTS}

\section{Right heart catheterisation}

Invasive measurements acquired in the $\mathrm{PH}$ patients are summarised in table 1 .

\section{CMR imaging}

Ventricular dimensions and systolic function of the $25 \mathrm{PH}$ patients and 12 controls are presented in table 2. In summary, RV end-diastolic volume, RV end-systolic volume, RVM and RVM index were significantly increased, and RVEF was significantly depressed in $\mathrm{PH}$ patients relative to control subjects. LV end-diastolic volume and LVSV were significantly lower in $\mathrm{PH}$ patients compared with controls. All LV measurements, in both $\mathrm{PH}$ patients and controls, were within previously published normal limits [29, 32]. Where available, CMR normal ranges determined by steady-state free precession imaging sequences similar to those employed in an earlier study have been used [32].

\section{Correlation analyses}

[NT-proBNP] was non-normally distributed in the population studied. Median (interquartile range) [NT-proBNP] was 669 (94-2615) $\mathrm{ng} \cdot \mathrm{L}^{-1}$. After logarithmic transformation, mean $\pm 1 \mathrm{SD}$ $\log _{10}$ [NT-proBNP] was $2.71 \pm 0.77$. A complete list of correlation

TABLE 1 Results of right heart catheterisation in 25
patients with pulmonary hypertension
Mean \pm SD




\begin{tabular}{|c|c|c|c|c|}
\hline \multirow[t]{2}{*}{ TABLE 2} & \multicolumn{4}{|c|}{$\begin{array}{l}\text { Ventricular dimensions and function by } \\
\text { cardiovascular magnetic resonance imaging in } \\
\text { patients with pulmonary hypertension (PH) and } \\
\text { controls }\end{array}$} \\
\hline & & PH & Controls & p-value \\
\hline \multirow{2}{*}{\multicolumn{2}{|c|}{$\begin{array}{l}\text { Subjects } \mathrm{n} \\
\text { Right ventricle }\end{array}$}} & 25 & 12 & \\
\hline & & & & \\
\hline \multicolumn{2}{|l|}{ EDV mL } & $170 \pm 57$ & $129 \pm 46$ & 0.033 \\
\hline \multicolumn{2}{|l|}{ ESV mL } & $99 \pm 53$ & $45 \pm 22$ & $<0.0001$ \\
\hline \multicolumn{2}{|c|}{ Stroke volume $\mathrm{mL}$} & $71 \pm 19$ & $83 \pm 29$ & 0.126 \\
\hline \multicolumn{2}{|c|}{ Ejection fraction \% } & $45 \pm 14$ & $66 \pm 7$ & $<0.0001$ \\
\hline \multicolumn{2}{|l|}{ Mass g } & $84 \pm 34$ & $48 \pm 18$ & 0.0002 \\
\hline \multicolumn{2}{|c|}{ RV mass index } & $0.87 \pm 0.24$ & $0.41 \pm 0.04$ & $<0.0001$ \\
\hline \multicolumn{5}{|l|}{ Left ventricle } \\
\hline \multicolumn{2}{|l|}{ EDV mL } & $86 \pm 25$ & $116 \pm 36$ & 0.005 \\
\hline \multicolumn{2}{|l|}{ ESV $\mathrm{mL}$} & $28 \pm 16$ & $31 \pm 14$ & 0.579 \\
\hline \multicolumn{2}{|c|}{ Stroke volume $\mathrm{mL}$} & $60 \pm 17$ & $85 \pm 24$ & 0.0009 \\
\hline \multicolumn{2}{|c|}{ Ejection fraction \% } & $71 \pm 9$ & $74 \pm 7$ & 0.218 \\
\hline \multicolumn{2}{|l|}{ Mass g } & $94 \pm 23$ & $120 \pm 51$ & 0.117 \\
\hline
\end{tabular}

Data are presented as mean $\pm \mathrm{SD}$, unless otherwise stated. EDV: end-diastolic volume; ESV: end-systolic volume; RV: right ventricular.

coefficients and accompanying p-values for variables compared with [NT-proBNP] is presented in table 3. There was a powerful negative logarithmic correlation between [NTproBNP] and RVEF (fig. 1). With the exception of LVSV, there was no significant correlation between [NT-proBNP] and LV measurements (see Discussion).

\section{Differences in $\log _{10}$ [NT-proBNP] in subgroups of $\mathrm{PH}$ patients}

There were no statistically significant differences in [NTproBNP] based on sex (mean $\log _{10}$ [NT-proBNP] was $2.7 \pm 0.6$ in males and $2.7 \pm 0.8$ in females) or aetiology of $\mathrm{PH}$ (mean $\log _{10}$ [NT-proBNP] was $2.6 \pm 0.8$ in PAH, $2.4 \pm 0.9$ in idiopathic $\mathrm{PAH}, 3.0 \pm 0.7$ in PAH-CTD and $3.0 \pm 0.5$ in patients with CTEPH).

\section{Right ventricular systolic dysfunction}

RVSD was present in nine out of $25 \mathrm{PH}$ patients (36\%). The distribution of [NT-proBNP] values for the nine patients with RVSD and the 16 patients without RVSD were normal. Mean [NT-proBNP] was significantly higher in patients with RVSD $\left(4,127 \pm 2,951 \mathrm{ng} \cdot \mathrm{L}^{-1}\right)$ in comparison with those without RVSD $\left(354 \pm 435 \mathrm{ng} \cdot \mathrm{L}^{-1} ; \mathrm{t}=3.813\right.$, degrees of freedom $\left.=8, \mathrm{p}=0.005\right)$.

\section{Diagnostic performance of NT-proBNP}

NT-proBNP performed best at a plasma concentration of 1,685 $\mathrm{ng} \cdot \mathrm{L}^{-1}$, detecting RVSD with $100 \%$ sensitivity $(95 \%$ confidence interval (CI) $63.0-100 \%$ ) and $94 \%$ specificity $(95 \%$ CI 71.3-99.9\%). A value of $1,685 \mathrm{ng} \cdot \mathrm{L}^{-1}$ was therefore chosen as the threshold value for RVSD detection.

Seventeen out of 25 patients had an [NT-proBNP] below the $1,685 \mathrm{ng} \cdot \mathrm{L}^{-1}$ threshold. Sixteen out of 17 of these patients were true negatives (i.e. RVEF was normal $(\geqslant 42 \%)$ ) and one was a false negative. In the false-negative subject, RVEF measured
$34 \%$ and [NT-proBNP] was $669 \mathrm{ng} \cdot \mathrm{L}^{-1}$. Thus, the negative predictive value of a low [NT-proBNP] was $94 \%$.

Eight out of 25 patients had an [NT-proBNP] $>1,685 \mathrm{ng} \cdot \mathrm{L}^{-1}$. RVSD was demonstrated by CMR imaging (RVEF $<42 \%$ ) in all of these individuals. Thus, the positive predictive value of a high [NT-proBNP] was $100 \%$. These results are presented graphically in figure 1 . Based on likelihood ratio testing, individuals with an [NT-proBNP] $>1,685 \mathrm{ng} \cdot \mathrm{L}^{-1}$ were 17 times more likely to have RVSD than those with below threshold results.

\section{Predictors of [NT-proBNP]}

Since RVEF correlated powerfully with RVM index ( $\mathrm{r}=-0.854$, $p<0.001)$, these variables were entered into two separate multivariable linear regression models in which [NT-proBNP] was the dependent variable. In these models, RVEF (odds ratio $(\mathrm{OR})=-0.035,95 \%$ CI $-0.052--0.018, \mathrm{p}<0.001)$ and RVM index $(\mathrm{OR}=2.254,95 \% \mathrm{CI} 1.403-3.106, \mathrm{p}<0.001)$ proved to be the only independent predictors of circulating [NT-proBNP].

\section{DISCUSSION}

In the current study, a close correlation between RVEF, measured directly by CMR imaging, and [NT-proBNP], is reported in patients with $\mathrm{PH}$, assessed before the initiation of any disease-targeted therapy. A previous study by NAGAYA et al. [12] demonstrated a similar relationship between RVEF, measured by electron beam CT imaging and BNP concentration, in a similar cohort of patients. The present study is of additional interest to this previous report for three important and clinically relevant reasons.

1) In routine clinical practice, most centres use NT-proBNP, not $\mathrm{BNP}$, to aid clinical decision making in heart failure and a variety of other conditions. As previously discussed, this is because NT-proBNP is more stable both in vivo and in vitro than the active BNP molecule itself [17].

2) The study by Nagaya et al. [12] used electron beam CT (EBCT) imaging to measure RVEF, while the present authors have utilised CMR imaging as their reference method. Temporal resolution is better with CMR imaging [33], without the need for ionising radiation or intravenous contrast [34]. As a result, CMR has emerged over recent years as the gold standard for detailed study of the right ventricle [9, 35-37], and has become an established modality for the physiological assessment of $\mathrm{PH}$ patients in cross-sectional studies [31, 38-40], longitudinal follow-up studies [41] and clinical trials of therapy [16]. EBCT, in contrast, is not routinely used to assess $\mathrm{PH}$ patients. The current study is therefore useful, as it defines the relationship between [NT-proBNP] and RV volumes and ejection fraction measured directly by CMR imaging.

3) In addition to a correlation between [NT-proBNP] and RVEF, the present authors found that an [NT-proBNP] $>1,685 \mathrm{ng} \cdot \mathrm{L}^{-1}$ (detected in eight out of 25 patients) proved a sensitive marker of RVSD ( $100 \%$ sensitivity). Below this threshold, only one false-negative result was returned, suggesting that RVSD is very unlikely when circulating [NTproBNP] is $<1,685 \mathrm{ng} \cdot \mathrm{L}^{-1}$, at least in patients assessed at baseline, before treatment initiation (negative predictive value $94 \%$ ). Stratifying patients on either side of this NT-proBNP 


\begin{tabular}{|c|c|c|c|}
\hline TABLE 3 & \multicolumn{3}{|c|}{$\begin{array}{l}\text { Correlation coefficients between } \log _{10}[\mathrm{NT} \text { - } \\
\text { proBNP] }\left(\mathrm{ng} \cdot \mathrm{L}^{-1}\right) \text { and measurements acquired in } \\
25 \text { pulmonary hypertension patients at } \\
\text { cardiovascular magnetic resonance imaging and } \\
\text { right heart catheterisation }\end{array}$} \\
\hline Variable & & $r$ coefficient & p-value \\
\hline \multicolumn{4}{|c|}{ Right ventricle } \\
\hline EDVI $\mathrm{mL} \cdot \mathrm{m}$ & & 0.556 & 0.004 \\
\hline ESVI $\mathrm{mL} \cdot \mathrm{m}$ & & 0.655 & $<0.001$ \\
\hline $\mathrm{SVI} \mathrm{mL} \cdot \mathrm{m}^{-2}$ & & -0.279 & 0.177 \\
\hline Ejection fra & ion \% & -0.66 & $<0.001$ \\
\hline Mass g & & 0.613 & 0.001 \\
\hline RV mass in & & 0.713 & $<0.001$ \\
\hline \multicolumn{4}{|c|}{ Left ventricle } \\
\hline EDVI $\mathrm{mL} \cdot \mathrm{m}$ & & -0.376 & 0.064 \\
\hline ESVI $\mathrm{mL} \cdot \mathrm{m}$ & & -0.08 & 0.705 \\
\hline $\mathrm{SVI} \mathrm{mL} \cdot \mathrm{m}^{-2}$ & & -0.508 & 0.01 \\
\hline Ejection fra & ion \% & -0.323 & 0.115 \\
\hline Mass g & & 0.196 & 0.349 \\
\hline \multicolumn{4}{|c|}{ Invasive measurements } \\
\hline Mean Ppa & & 0.501 & 0.011 \\
\hline Systolic $P p$ & & 0.435 & 0.03 \\
\hline Diastolic $P_{k}$ & & 0.622 & $<0.001$ \\
\hline Cardiac ino & & -0.523 & 0.007 \\
\hline $\begin{array}{l}\text { Pulmonary } \\
\text { resistanc }\end{array}$ & ascular & -0.566 & 0.003 \\
\hline $\mathrm{Sv}, \mathrm{O}_{2}$ & & -0.541 & 0.009 \\
\hline \multicolumn{4}{|c|}{$\begin{array}{l}\text { EDVI: end-diastolic volume index; ESVI: end-systolic volume index; SVI: stroke } \\
\text { volume index; Ppa: pulmonary artery pressure; } \mathrm{Sv}_{2} \mathrm{O}_{2} \text { : mixed venous oxygen } \\
\text { saturation. }\end{array}$} \\
\hline
\end{tabular}

threshold may prove useful as an operator-independent, objective means of classifying individuals at presentation based upon their probability of having RVSD and, thus, an increased risk of early death.

\section{Physiological determinants of [NT-proBNP]}

Several variables correlated closely with circulating [NTproBNP] in the present study (table 3). Of these variables, only RVEF and RVM index, analysed within separate regression models to avoid the effects of colinearity, proved independent predictors of [NT-proBNP]. Although the RVM index relates linearly to mean $P$ pa in $\mathrm{PH}$ [31], it has not been proven to predict early death in patients with this condition. For this reason, the current authors sought to detect RVSD, not RV hypertrophy, using [NT-proBNP], however the influence of RV hypertrophy (as described by RVM index) should be acknowledged as a potential confounder of the present study's results. The vast majority (seven out of eight $(88 \%)$ ) of patients in the present study with above-threshold [NT-proBNP] levels, indicative of RVSD, also had RV hypertrophy (defined as an $\mathrm{RVM}>84 \mathrm{~g}$ ( $>2$ SDs above the mean RV mass of the control population $(48 \pm 18 \mathrm{~g})$ ), reflecting the covariation between RVM index, RVEF and [NT-proBNP] that was found. Despite this, RVEF appeared to be an important determinant of circulating [NT-proBNP] in the current study.

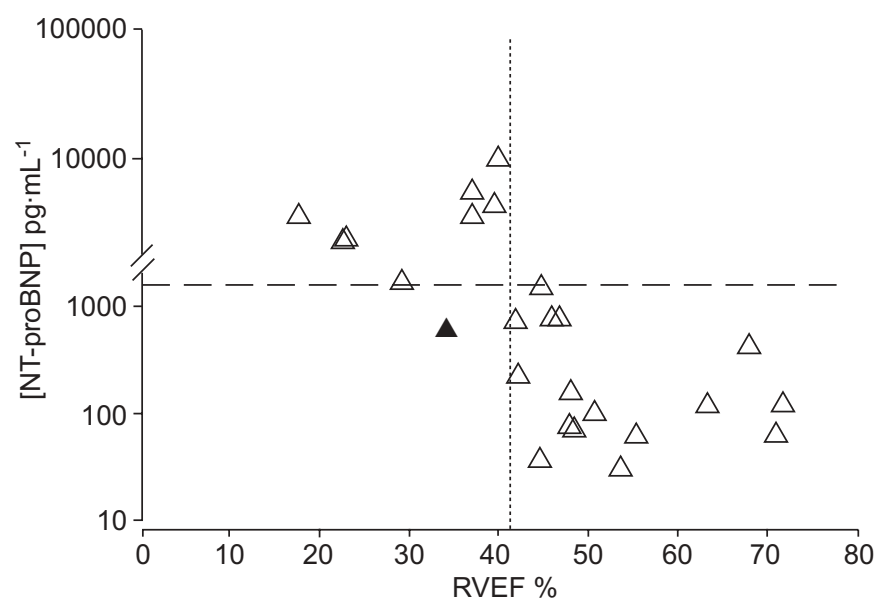

FIGURE 1. Cardiovascular magnetic resonance imaging and N-terminal B-type natriuretic peptide (NT-proBNP) measurements were acquired in 25 patients with pulmonary hypertension. After logarithmic transformation, NT-proBNP concentration ([NT-proBNP]) correlated powerfully with right ventricular ejection fraction (RVEF) $(r=-0.66, p<0.001)$. - - - the [NT-proBNP] threshold chosen $\left(1,685 \mathrm{ng} \cdot \mathrm{L}^{-1}\right)$ for the detection of RV systolic dysfunction (RVSD); $\cdots \cdots \cdots \cdot$. the RVEF (42\%) used to define RVSD. Only one false-negative result $(\boldsymbol{\Delta})$ was returned.

\section{Clinical implications}

A recent study reported by QUAIFE et al. [42] demonstrated a close correlation between RVEF and RV wall stress, which is the principal stimulus to NT-proBNP release in $\mathrm{PH}$. This relationship may explain the usefulness of NT-proBNP as a means of detecting RVSD reported herein. In interpreting the present results, it is worth considering the findings of FIJALKOWSKA et al. [19], who recently examined the prognostic significance of NT-proBNP in PH. Nonsurvivors in this study were identified by an [NT-proBNP] $>1,400 \mathrm{ng} \cdot \mathrm{L}^{-1}$. Since nonsurvivors with $\mathrm{PH}$ are likely to die from RV failure, and [NT-proBNP] correlated powerfully with echocardiographic measures of RV systolic function in the study by FIJALKOWSKA et al. [19], it seems plausible that the $1,400 \mathrm{ng} \cdot \mathrm{L}^{-1}$ threshold reported by FIJALKOWSKA et al. [19] and the present study's threshold of $1,685 \mathrm{ng} \cdot \mathrm{L}^{-1}$ reflect genuine RVSD in the patients studied.

Clearly, the true clinical significance of the [NT-proBNP] threshold for RVSD $\left(1,685 \mathrm{ng} \cdot \mathrm{L}^{-1}\right)$ identified in the present study can only be determined in a longitudinal survival analysis. For this reason, it is difficult to justify detailed proposals for the future use of NT-proBNP in clinical practice at this time. However, our findings indicate that NT-proBNP, measured during a patient's first consultation at a specialist $\mathrm{PH}$ centre, could, in conjunction with existing means of assessing RV function (i.e. clinical examination and echocardiography), help to identify patients with prognostically significant RVSD. Assuming other reasons for a high NTproBNP were excluded, patients with a high [NT-proBNP] could then be invasively assessed at an early stage and treatment initiated if appropriate. Although there is as yet no evidence that early treatment of $\mathrm{PH}$ alters prognosis per se, it is known that a history of overt RV failure before treatment initiation is associated with an increased mortality risk [43]. Prompt initiation of therapy in patients with high NT-proBNP 
levels and subclinical RVSD may, therefore, avoid the development of overt RV failure and reduce early mortality.

\section{$R V$ ejection fraction}

In the current study, RVEF was utilised to define RVSD. Although historical data have suggested that RVEF does not reflect RV systolic function alone (since it is also dependant upon right ventricular afterload) [44-46], RVEF determined by echocardiography and radionuclide ventriculography has recently been shown to predict adverse outcomes (cardiac death or deterioration) in patients with $\mathrm{PH}$ [47]. However, until longitudinal survival studies are reported in which CMRderived variables are assessed, the true prognostic significance of CMR-derived RVEF, and the cut-off value of $42 \%$ used here to define RVSD cannot be known.

\section{NT-proBNP and LV stroke volume}

A statistically significant relationship between [NT-proBNP] and LVSV was found, but there was no correlation between [NT-proBNP] and RVSV. This apparent contradiction reflects the inaccuracy of CMR planimetry in determining true (i.e. forward) stroke volume in patients with significant valvular regurgitation. CMR planimetry of a dilated RV with significant tricuspid valve regurgitation will always overestimate true forward RVSV because a proportion of the ejected blood volume will move backwards through the incompetent tricuspid valve. Since forward LVSV and forward RVSV will, over several heart beats, be equivalent in the absence of any communicating shunt, and since no $\mathrm{PH}$ patient in the present study had any evidence of mitral regurgitation, the statistically significant relationship that was found between LVSV and [NT-proBNP] is likely to reflect an underlying correlation between [NT-proBNP] and true forward RVSV that is obscured by this predictable measurement error. Although CMR planimetry may not always accurately determine forward RVSV in PH patents, RVEF still reflects the systolic contractile function of the ventricle, assessment of which was the primary aim of the present study. An alternative confounder to the CMR planimetry results might be the trabeculation of the RV. Despite this concern, acceptable intra-observer variation has been found for ventricular mass and ejection fraction (3.8-7.4 and $3.4-4.4 \%$, respectively) measured by this method in the Glasgow Cardiac Magnetic Resonance Unit (unpublished data).

\section{Study limitations}

The relatively small number of patients involved in the present study is of concern in the proposal of a specific cut-off level for use in the detection of RVSD in clinical practice. However, CMR imaging represents an extremely accurate and reproducible gold standard of RVEF, limiting the number of patients required for such studies. [NT-proBNP] can be affected by a number of factors, including renal function, left-sided heart disease, age, sex [48] and recent exertion. In the current study, patients with other reasons for a high [NT-proBNP] were excluded, and the timing and the conditions surrounding NTproBNP sampling were standardised. A recent study has reported a close relationship between $S_{\mathrm{v}, \mathrm{O}_{2}}$ and [NT-proBNP] in patients with cyanotic congenital heart disease and $\mathrm{PH}$ [49]; however, $\mathrm{S}_{\mathrm{v}} \mathrm{O}_{2}$ did not predict [NT-proBNP] in the present study, and patients with CHD were specifically excluded. The present authors wish to emphasise that their conclusions can only be applied to selected $\mathrm{PH}$ patients assessed in the described manner. In addition, it is not known whether therapies such as sildenafil, which acts directly upon the cardiac myocyte [50], will affect the relationship reported herein between RVEF and [NT-pro BNP], or whether any observed fall in [NT-pro BNP] during treatment will prove proportional to an improvement in RV systolic function. Further insight into these issues is necessary to understand the clinical significance of changes in [NT-proBNP] during treatment.

\section{Conclusion}

The present study is the first to utilise a specific N-terminal Btype natriuretic peptide threshold concentration $\left(1,685 \mathrm{ng} \cdot \mathrm{L}^{-1}\right)$ as a means of detecting right ventricular systolic dysfunction in patients with pulmonary hypertension. The method that is described for classifying patients either side of such a threshold is simple, inexpensive and, most importantly, non-invasive and it may help to inform the largely subjective process of stratifying new patients for invasive assessment and the initiation of disease-targeted therapy.

\section{REFERENCES}

1 D'Alonzo GE, Barst RJ, Ayres SM, et al. Survival in patients with primary pulmonary hypertension. Results from a national prospective registry. Ann Intern Med 1991; 115: 343-349.

2 Eysmann SB, Palevsky HI, Reichek N, Hackney K, Douglas PS. Two-dimensional and Doppler-echocardiographic and cardiac catheterization correlates of survival in primary pulmonary hypertension. Circulation 1989; 80: 353-360.

3 Fuster V, Steele PM, Edwards WD, Gersh BJ, McGoon MD, Frye RL. Primary pulmonary hypertension: natural history and the importance of thrombosis. Circulation 1984; 70: 580-587.

4 Kanemoto N. Natural history of pulmonary hemodynamics in primary pulmonary hypertension. Am Heart $J$ 1987; 114: 407-413.

5 Kawut SM, Horn EM, Berekashvili KK, et al. New predictors of outcome in idiopathic pulmonary arterial hypertension. Am J Cardiol 2005; 95: 199-203.

6 Galie N, Torbicki A, Barst R, et al. Guidelines on diagnosis and treatment of pulmonary arterial hypertension. The Task Force on Diagnosis and Treatment of Pulmonary Arterial Hypertension of the European Society of Cardiology. Eur Heart J 2004; 25: 2243-2278.

7 Yeo TC, Dujardin KS, Tei C, Mahoney DW, McGoon MD, Seward JB. Value of a Doppler-derived index combining systolic and diastolic time intervals in predicting outcome in primary pulmonary hypertension. Am J Cardiol 1998; 81: 1157-1161.

8 Lorenz CH, Walker ES, Graham TP Jr, Powers TA. Right ventricular performance and mass by use of cine MRI late after atrial repair of transposition of the great arteries. Circulation 1995; 92: Suppl. 9, II233-II239.

9 Pennell D, Casolo G. Right ventricular arrhythmia: emergence of magnetic resonance imaging as an investigative tool. Eur Heart J 1997; 18: 1843-1845. 
10 King L, Wilkins MR. Natriuretic peptide receptors and the heart. Heart 2002; 87: 314-315.

11 Leuchte $\mathrm{HH}$, Holzapfel M, Baumgartner RA, et al. Clinical significance of brain natriuretic peptide in primary pulmonary hypertension. J Am Coll Cardiol 2004; 43: 764770.

12 Nagaya N, Nishikimi T, Okano Y, et al. Plasma brain natriuretic peptide levels increase in proportion to the extent of right ventricular dysfunction in pulmonary hypertension. J Am Coll Cardiol 1998; 31: 202-208.

13 Nagaya N, Nishikimi T, Uematsu M, et al. Plasma brain natriuretic peptide as a prognostic indicator in patients with primary pulmonary hypertension. Circulation 2000; 102: 865-870.

14 Park MH, Scott RL, Uber PA, Ventura HO, Mehra MR. Usefulness of B-type natriuretic peptide as a predictor of treatment outcome in pulmonary arterial hypertension. Congest Heart Fail 2004; 10: 221-225.

15 Nagaya N, Ando M, Oya H, et al. Plasma brain natriuretic peptide as a noninvasive marker for efficacy of pulmonary thromboendarterectomy. Ann Thorac Surg 2002; 74: 180184.

16 Wilkins MR, Paul GA, Strange JW, et al. Sildenafil versus Endothelin Receptor Antagonist for Pulmonary Hypertension (SERAPH) study. Am J Respir Crit Care Med 2005; 171: 1292-1297.

17 Downie PF, Talwar S, Squire IB, Davies JE, Barnett DB, $\mathrm{Ng}$ LL. Assessment of the stability of N-terminal pro-brain natriuretic peptide in vitro: implications for assessment of left ventricular dysfunction. Clin Sci (Lond) 1999; 97: 255258.

18 Souza R, Bogossian HB, Humbert M, et al. N-terminal-probrain natriuretic peptide as a haemodynamic marker in idiopathic pulmonary arterial hypertension. Eur Respir J 2005; 25: 509-513.

19 Fijalkowska A, Kurzyna M, Torbicki A, et al. Serum Nterminal brain natriuretic peptide as a prognostic parameter in patients with pulmonary hypertension. Chest 2006; 129: 1313-1321.

20 Nagaya N, Nishikimi T, Uematsu M, et al. Secretion patterns of brain natriuretic peptide and atrial natriuretic peptide in patients with or without pulmonary hypertension complicating atrial septal defect. Am Heart J 1998; 136: 297-301.

21 Ndrepepa G, Braun S, Mehilli J, et al. Plasma levels of Nterminal pro-brain natriuretic peptide in patients with coronary artery disease and relation to clinical presentation, angiographic severity, and left ventricular ejection fraction. Am J Cardiol 2005; 95: 553-557.

22 Arakawa N, Nakamura M, Aoki H, Hiramori K. Plasma brain natriuretic peptide concentrations predict survival after acute myocardial infarction. J Am Coll Cardiol 1996; 27: 1656-1661.

23 Groenning BA, Nilsson JC, Sondergaard L, et al. Detection of left ventricular enlargement and impaired systolic function with plasma N-terminal pro brain natriuretic peptide concentrations. Am Heart J 2002; 143: 923-929.

24 Pedersen F, Raymond I, Kistorp C, Sandgaard N, Jacobsen P, Hildebrandt P. N-terminal pro-brain natriuretic peptide in arterial hypertension: a valuable prognostic marker of cardiovascular events. J Card Fail 2005; 11: Suppl. 5, S70-S75.

25 Golbasy Z, Ucar O, Yuksel AG, Gulel O, Aydogdu S, Ulusoy V. Plasma brain natriuretic peptide levels in patients with rheumatic heart disease. Eur J Heart Fail 2004; 6: 757-760.

26 Luchner A, Hengstenberg C, Lowel H, Riegger GA, Schunkert H, Holmer S. Effect of compensated renal dysfunction on approved heart failure markers: direct comparison of brain natriuretic peptide (BNP) and Nterminal pro-BNP. Hypertension 2005; 46: 118-123.

27 Magnusson $M$, Melander $\mathrm{O}$, Israelsson B, Grubb A, Groop L, Jovinge S. Elevated plasma levels of Nt-proBNP in patients with type 2 diabetes without overt cardiovascular disease. Diabetes Care 2004; 27: 1929-1935.

28 Simonetti OP, Kim RJ, Fieno DS, et al. An improved MR imaging technique for the visualization of myocardial infarction. Radiology 2001; 218: 215-223.

29 Lorenz CH, Walker ES, Morgan VL, Klein SS, Graham TP Jr. Normal human right and left ventricular mass, systolic function, and gender differences by cine magnetic resonance imaging. J Cardiovasc Magn Reson 1999; 1: 7-21.

30 Sievers B, Kirchberg S, Bakan A, Franken U, Trappe HJ. Impact of papillary muscles in ventricular volume and ejection fraction assessment by cardiovascular magnetic resonance. J Cardiovasc Magn Reson 2004; 6: 9-16.

31 Saba TS, Foster J, Cockburn M, Cowan M, Peacock AJ. Ventricular mass index using magnetic resonance imaging accurately estimates pulmonary artery pressure. Eur Respir J 2002; 20: 1519-1524.

32 Alfakih K, Plein S, Thiele H, Jones T, Ridgway JP, Sivananthan MU. Normal human left and right ventricular dimensions for MRI as assessed by turbo gradient echo and steady-state free precession imaging sequences. $J$ Magn Reson Imaging 2003; 17: 323-329.

33 Lembcke A, Dohmen PM, Dewey M, et al. Multislice computed tomography for preoperative evaluation of right ventricular volumes and function: comparison with magnetic resonance imaging. Ann Thorac Surg 2005; 79: 13441351.

34 Raman SV, Shah M, McCarthy B, Garcia A, Ferketich AK. Multi-detector row cardiac computed tomography accurately quantifies right and left ventricular size and function compared with cardiac magnetic resonance. Am Heart J 2006; 151: 736-744.

35 Longmore DB, Klipstein RH, Underwood SR, et al. Dimensional accuracy of magnetic resonance in studies of the heart. Lancet 1985; 1: 1360-1362.

36 MacNee W. Pathophysiology of cor pulmonale in chronic obstructive pulmonary disease. Part one. Am J Respir Crit Care Med 1994; 150: 833-852.

37 Mogelvang J, Stubgaard M, Thomsen C, Henriksen O. Evaluation of right ventricular volumes measured by magnetic resonance imaging. Eur Heart J 1988; 9: 529-533.

38 Blyth KG, Groenning BA, Martin TN, et al. Contrast enhanced-cardiovascular magnetic resonance imaging in patients with pulmonary hypertension. Eur Heart J 2005; 26: 1993-1999.

39 Roeleveld RJ, Marcus JT, Faes TJ, et al. Interventricular septal configuration at MR imaging and pulmonary arterial pressure in pulmonary hypertension. Radiology 2005; 5: 5. 
40 Vonk Noordegraaf A, Gan T, Marcus J, Boonstra A, Postmus P. Interventricular mechanical asynchrony is an important cause of cardiac dysfunction in pulmonary hypertension. Eur Respir J 2004; 24: Suppl. 48, 203s.

41 Roeleveld RJ, Vonk-Noordegraaf A, Marcus JT, et al. Effects of epoprostenol on right ventricular hypertrophy and dilatation in pulmonary hypertension. Chest 2004; 125 : 572-579.

42 Quaife RA, Chen MY, Lynch D, et al. Importance of right ventricular end-systolic regional wall stress in idiopathic pulmonary arterial hypertension: a new method for estimation of right ventricular wall stress. Eur J Med Res 2006; 11: 214-220.

43 Sitbon O, Humbert M, Nunes H, et al. Long-term intravenous epoprostenol infusion in primary pulmonary hypertension: prognostic factors and survival. J Am Coll Cardiol 2002; 40: 780-788.

44 Brown KA, Okada RD, Boucher CA, Strauss HW, Pohost GM. Right ventricular ejection fraction response to exercise in patients with coronary artery disease: influence of both right coronary artery disease and exercise-induced changes in right ventricular afterload. $J$ Am Coll Cardiol 1984; 3: 895-901.

45 Konstam MA, Salem DN, Isner JM, et al. Vasodilator effect on right ventricular function in congestive heart failure and pulmonary hypertension: end-systolic pressure-volume relation. Am J Cardiol 1984; 54: 132-136.

46 Morrison D, Goldman S, Wright AL, et al. The effect of pulmonary hypertension on systolic function of the right ventricle. Chest 1983; 84: 250-257.

47 Zafrir N, Zingerman B, Solodky A, et al. Use of noninvasive tools in primary pulmonary hypertension to assess the correlation of right ventricular function with functional capacity and to predict outcome. Int J Cardiovasc Imaging 2006; [Epub ahead of print PMID:16972146].

48 Raymond I, Groenning BA, Hildebrandt PR, et al. The influence of age, sex and other variables on the plasma level of $\mathrm{N}$-terminal pro brain natriuretic peptide in a large sample of the general population. Heart 2003; 89: 745-751.

49 Hopkins WE, Chen Z, Fukagawa NK, Hall C, Knot HJ, LeWinter MM. Increased atrial and brain type natriuretic peptides in adults with cyanotic congenital heart disease: enhanced understanding of the relationship between hypoxia and natriuretic peptide secretion. Circulation 2004; 15: 2872-2877.

50 Das A, Xi L, Kukreja RC. Phosphodiesterase-5 inhibitor sildenafil preconditions adult cardiac myocytes against necrosis and apoptosis. Essential role of nitric oxide signaling. J Biol Chem 2005; 280: 12944-12955. 